\title{
Neuronal Alterations and Antioxidant Status of Lipopolysaccharide Induced Neuronal damage in Mice: Efficacy of Three Medicinal Plants
}

\author{
B. P. Olatunji ${ }^{1,2^{*}}$, T. R. Fasola ${ }^{2}$, S. A. Onasanwo ${ }^{3}$, A. J. Akinyemi ${ }^{4}$, P. A. Adeniyi ${ }^{5}$, A. O. Ishola ${ }^{5}$ \\ ${ }^{1}$ Department of Biological Sciences, College of Sciences, Afe Babalola University, Ado Ekiti, Nigeria. ${ }^{2}$ Department of Botany, \\ University of Ibadan, Nigeria. ${ }^{3}$ Department of Physiology, University of Ibadan, Nigeria., ${ }^{4}$ Department of Biochemistry, College of Medicine, \\ Afe Babalola University, Ado Ekiti, Nigeria. ${ }^{5}$ Department of Anatomy, College of Medicine, Afe Babalola University, Ado Ekiti, Nigeria.
}

\begin{tabular}{l} 
ARTICLE INFO \\
\hline Article history: \\
Received on: 28/06/2016 \\
Accepted on: 29/05/2017 \\
Available online: $30 / 12 / 2017$ \\
\hline Key words: \\
Neuroinflammation, \\
Scoparia dulcis, Bacopa \\
floribunda, Cordia millenii, \\
Lipopolysaccharide.
\end{tabular}

\begin{abstract}
Background: Several factors including neuroinflammation and oxidative stress formation contribute to the progression and development of cognitive impairment. Lipopolysaccharide (LPS) injection has been used as non-transgenic mouse models for Alzheimer's diseases (AD). Plant medicine has been proposed to be the prospect in treatment/ management of neurodegenerative disease.

Aim: The present study sought to evaluate the effect of three medicinal plants (Bacopa floribunda (R.Br)Wettst, Scoparia dulcis L and Cordia millenii Bak.) locally used for memory enhancement on neuronal histology and antioxidant status against Lipopolysaccharide induced neuronal damage in mice.

Methods: Forty-nine (49) BALB/c male mice were randomly grouped into seven (7) groups of 7 mice each. All animals except in group I control (vehicle), were injected intraperitoneally (I.P.) with LPS ( $250 \mu \mathrm{g} / \mathrm{kg}$ ) once, after oral pre-treatment with plant extracts and control drugs for 7 days. Group II (untreated) received LPS only $(250 \mu \mathrm{g} / \mathrm{kg})$, group III received LPS + Sulindac Sulfide $(\mathrm{SS}, 4 \mathrm{mg} / \mathrm{kg})$, group IV received LPS + Donepezil (DPZ, $1 \mathrm{mg} / \mathrm{kg}$ ) group V, VI, and VII received LPS $+200 \mathrm{mg} / \mathrm{kg}$ of plant extracts [Scoparia dulcis (SD), Bacopa floribunda (BF), and Cordia millenii (CM)] respectively. After the experiment, histological analysis of the hippocampus from the whole brain was carried out while the other brain tissues comprising frontal cortex and cerebellum were used for determination of biomarkers of antioxidant status such as catalase (CAT); superoxide dismutase (SOD); malondialdehyde (MDA) and reduced glutathione (GSH).

Results: Oral administration of LPS induced neuronal damage through cell death as evidenced by the histological analysis and altered brain antioxidant status in mice. However, the plant extracts were able to prevent such neuronal alterations and restored the antioxidant status when compared to the LPS induced neuronal damage in mice.

Conclusion: LPS induced neuroinflammation was prevented by the extracts of; B. floribunda, S. dulcis and C. millenni. Neural damage was also prevented by the extracts. This activity could be attributed to their antioxidant potential as evidenced from their inhibitory effect on MDA and increased CAT activity and GSH. Nevertheless, other possible mechanisms of action against neuronal damage need to be assessed to further justify their use traditionally in the treatment/management of neurodegenerative diseases.
\end{abstract}

\section{INTRODUCTION}

Neurodegenerative disorders such as Alzheimer's disease $(\mathrm{AD})$ and Parkinson disease (PD) are common among the

*Corresponding Author

Email: walersm_@yahoo.com; olatunjibp @ abuad.edu.ng Tel: $+234(0) 80 \overline{6} 5302521$ elderly ones and characterized by progressive cognitive deficits and behavioral disturbances (Norton et al., 2014). Several complex pathogenic pathways have been found to be involved in the disease development and progression, which include amyloid beta accumulation, neurofibrillary tangle formation (Terry and Masliah, 1991), cholinergic deficit and oxidative stress (Perry et al., 2002, Frank and Gupta, 2005; Dastmalchi et al., 2007; Norton et al., 2014). 
The contribution of the inflammatory component of diverse disorders to disease progression has led to novel attempts aimed at discovering ways to attenuate inflammation therapeutically (Nathan, 2002). Neuroinflammation and oxidative stress play crucial role in the pathogenesis of chronic neurodegenerative diseases such as AD. However, aberrant activation due to diverse stimulus is neurotoxic and often detrimental leading to neurodegeneration (Streit et al., 2004). Previous studies have implicated oxidative stress to play a crucial role in neurodegenerative diseases such as $\mathrm{AD}$ via lipid peroxidation of cell membrane of the neurons (Pratico and Delanty 2000; Oboh et al., 2012). Excessive oxidative stress is thought to have an important role in the pathogenesis of autoimmune diseases by enhancing the inflammation, inducing apoptotic cell death (Kumagai et al., 2003).

Lipopolysaccharides (LPS), a component of Gramnegative bacterial cell wall has been reported to initiate neuroinflamation by activating the microglia cells and induce changes within the hippocampus and entorhinal cortex. (Dobrovolskaia and Vogel, 2002, Min et al., 2009). This peripheral inflammatory milieu can be relayed to the central nervous system through vagus nerve activation, circumventricular organs and brain endothelial cell activation (Ching et al., 2007, Akrout et al., 2009). The systemic administration of LPS activates microglia leading to neurodegeneration, suppression of neurogenesis and impairment of cognitive behavior in mice and rats (Qin et al., 2007, Lee et al., 2008; Okun et al., 2010). LPS have also been shown to damage neurons by causing oxidative stress through depletion in the levels of antioxidant enzymes which foster free radical generation by increasing brain MDA and reduction in GSH content (Kheir-Eldin et al., 2001; Sebai et al., 2009). Therefore, use of antioxidants has been recognized as an effective method in minimizing pathological and toxic effects associated with oxidative stress caused by neurotoxic agents. Numerous ethnomedicinal plants have been used to treat several cognitive disorders including Alzheimer's disease. They act as excellent antioxidants, anti-inflammatory mediators, cholinesterase and $\beta$-secretase inhibitors. In addition, these natural compounds also prevent the accumulation of amyloid beta and its fibril formation (Khan et al., 2012). Besides acting as core-molecules, these natural compounds act as a template for the production and synthesis of several drug leads with improved pharmacokinetic potentials and greater efficacies. Hence, medicinal herbs that have interesting pharmacological effects with noticeable antiAlzheimer's disease potential deserves increased attention for further development to drug entities.

Ethnobotanical survey of plants locally used for memory enhancement among the Yoruba people of Southwestern Nigeria indicated that of all the species used, three different plants Bacopa floribunda Scoparia dulcis belonging to the family Scrophulariaceae and Cordia millenii family Bignoniaceae are more frequently used. A literature search has revealed that numerous traditional medicinal plants have been used to treat several cognitive disorders including Alzheimer's disease. They act as excellent antioxidants, anti-inflammatory mediators, cholinesterase and $\beta$-secretase inhibitors. (Oken et al., 1995, Skolnick, 1997; Durairajan et al., 2008). Although, Bacopa floribunda, Scoparia dulcis and Cordia millenii plants are currently being used for memory enhancement and management/treatment of neurodegenerative diseases in folkmedicine, there are limited scientific studies on their neuroprotective effect. Hence, the current study sought to investigate their neuroprotective effect against LPS-induced neuroinflammation in mice. In this context, we assessed the efficacy of the three plants in ameliorating the inflammation of the neuronal cells through histo-morphological analysis and preventing oxidative stress through biomarkers of antioxidant status.

\section{MATERIALS AND METHODS}

\section{Sample collection and preparation of plant extracts}

Fresh samples of the plant materials (Bacopa floribunda, Scoparia dulcis and Cordia millenni) were obtained from a farmland at Ado-Ekiti metropolis, Nigeria. Authentication of the plants was carried out at the Department of Botany, Ekiti State University, Ado-Ekiti, Nigeria. The samples were air dried at ambient room temperature and made into powdery form using a grinder. The plant extracts were prepared by refluxing $\left(50-60{ }^{\circ} \mathrm{C}\right)$ $10 \mathrm{~g}$ of each sample with $100 \mathrm{ml} 80 \%$ ethanol for $30 \mathrm{~min}$. This was repeated thrice with fresh solvent each time, followed by filtration using muslin cloth and the filtrate was lyophilized to dryness. The lyophilized samples were collected and stored at -20 ${ }^{0} \mathrm{C}$ until use for subsequent analysis Kumar et al., 2012.

\section{Animals}

Forty nine (49) BALB/c male mice weighing between 25-30 g were obtained from the central animal house, College of Medicine, Afe Babalola University Ado Ekiti, Nigeria. They were caged, maintained at room temperature under standard 12-12 h light-dark cycle and allowed free access to water and commercially produced diet ad libitum. Treatment protocols were in accordance with the ethical requirements of the Animal Care and Use Research Ethics Committee of the University of Ibadan, Nigeria with approval number (UI-ACUREC/16/0043).

\section{Experimental Protocol}

In this study, $49 \mathrm{BALB} / \mathrm{c}$ male mice were divided into seven groups of 7 animals each $(n=7)$. All animals except for group I (control) received saline (vehicle), were injected intraperitoneally (ip) with $250 \mu \mathrm{g} / \mathrm{kg}$ of Lipopolysaccharide (LPS). For all experiments, LPS (Escherichia coli, serotype 055:B5, Sigma, St. Louis, MO, USA) induced an inflammatory response and was injected once (ip) after oral pre-treatment with plant extracts and control drugs for 7 days. Group II received LPS (Control) only, group III received LPS + Sulindac Sulfide (SS, 4 $\mathrm{mg} / \mathrm{kg}$ ) an anti-inflamatory agent, group IV received LPS + Donepezil (DPZ, $1 \mathrm{mg} / \mathrm{kg}$ ) a standard drug for the treatment of 
AD), group V LPS + Scoparia dulcis (SD) at $200 \mathrm{mg} / \mathrm{kg}$, Group VI received Bacopa floribunda (BF) at $200 \mathrm{mg} / \mathrm{kg}$, group VII received Vehicle + LPS Cordia millenii $(\mathrm{CM})$ at $200 \mathrm{mg} / \mathrm{kg}$. The choice of this dose of $200 \mathrm{mg} / \mathrm{kg}$ of plant extracts was made on the basis of our preliminary study that used the same concentration and obtained beneficial result with no toxic effect on the brain of mice. All injections were administered $4 \mathrm{hrs}$ prior to sacrifice of the animals. This allows enough time for the development of neuroinflammation (most notably in Hippocampus) at this dose and similar doses of intraperitoneal LPS (Vernetder et al., 1998). Except for LPS injected intraperitoneally, all the drugs and extracts were reconstituted in the vehicle (normal saline) and were administered orally. The dosage for the administration was carried out using $1 \mathrm{ml}$ per $1 \mathrm{~kg}$ animal body weight.

\section{Animal Sacrifice}

After the completion of experiment, mice were decapitated under mild diethyl ether anesthesia and the cerebral tissue (whole-brain) was rapidly dissected and placed on ice and weighed.

\section{Preparation of brain homogenates}

The brain tissue ( $\mathrm{n}=5)$ was subsequently homogenized in cold 0.1 M phosphate buffer, $\mathrm{pH} 8.0$ ), with about 10-up-and-down strokes at approximately $1200 \mathrm{rev} / \mathrm{min}$ in a Teflon-glass homogenizer. The homogenate was centrifuged for $10 \mathrm{~min}$ at 3000 rpm to yield a pellet that was discarded and a low-speed supernatant was kept for antioxidant assay. Antioxidant potential was determined in both the brain tissue and serum by measuring activities of superoxide dismutase (SOD), catalase (CAT), Malondialdehyde (MDA), and reduced glutathione (GSH) in whole-brain homogenates according to the method of Ohkawa et al. (1979).

\section{Histology procedure}

Brain tissue $(n=2)$ from each group were transferred to $10 \%$ formal saline for fixation. After which they processed for histological staining of the hippocampus using Hematoxylin and Eosin (H\&E) stain.

\section{RESULTS}

\section{Effect of LPS-Induced Neuronal Damage on Some Oxidative Stress Biomarkers}

Figure 1 and Fig. 2 shows the malondialdehyde (MDA) level in all the experimental groups in the brain homogenates and serum respectively. There was significant increase $(p<0.01)$ in the level of MDA both in the brain tissue and blood serum of the untreated LPS-induced mice when compared with the vehicle group. In addition, there was also significant difference in the treated groups SS, DPZ and BF which were significantly reduced $(\mathrm{p}<0.05)$ when compared with untreated LPS-induced mice. However, CM showed a decrease (non-significant) in MDA concentration of the brain homogenate but a better activity was observed in the serum.

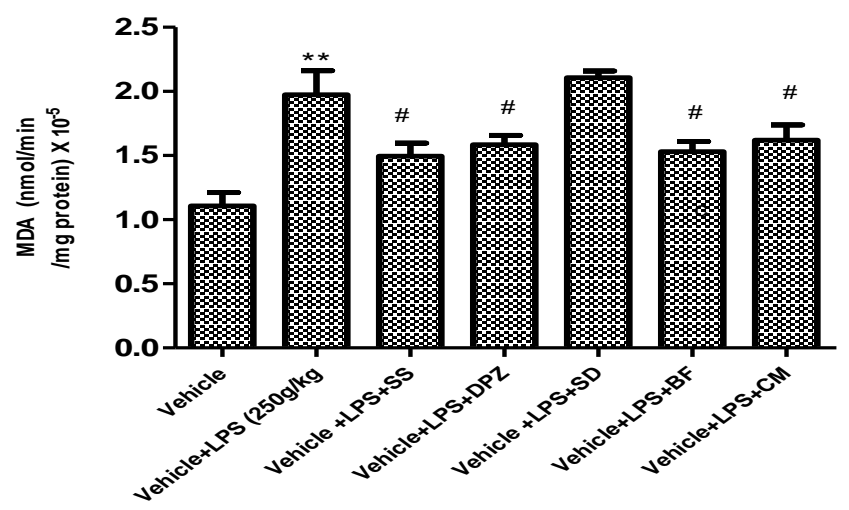

Fig. 1: Mice Brain MDA Status; Effect of Orally Administered Three Medicinal Plants for 7 Days. The MDA levels in whole brain tissue (Fig.1). Values were expressed as mean \pm S.E.M values ( $n=5$ /group) and analyzed by one-way ANOVA and multiple comparisons were performed by Tukey HSD test. A criterion of significance was accepted and marked as P $<0.05$ (\#) and 0.01 (** or \#\#). The mark of * is LPS group versus Vehicle group and the mark of \# is each treatment group versus LPS group ns; not significant.

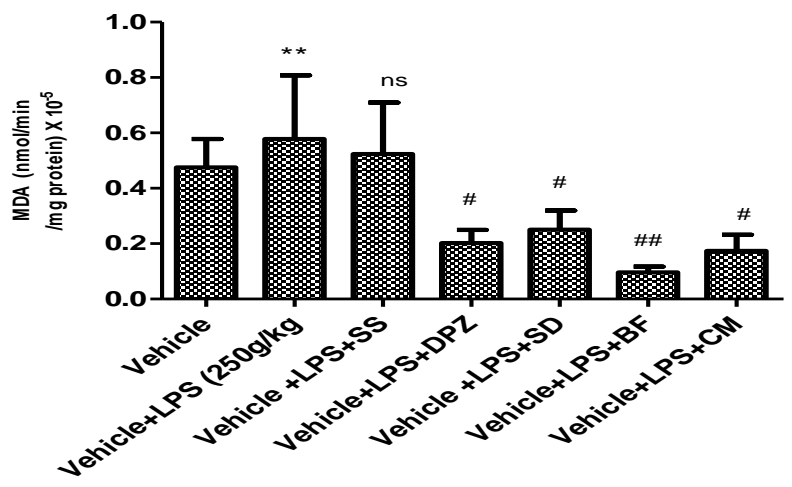

Fig. 2: Mice Serum MDA Status; Effect of Orally Administered Three Medicinal Plants for 7 Days. The MDA levels in the blood serum (Fig. 2). Values were expressed as mean \pm S.E.M values $(n=5$ /group) and analyzed by one-way ANOVA and multiple comparisons were performed by Tukey HSD test. A criterion of significance was accepted and marked as P $<0.05$ (\#) and 0.01 (** or \#\#). The mark of * is LPS group versus Vehicle group and the mark of \# is each treatment group versus LPS group ns; not significant.

Tables 1 and 2 showed the biochemical parameters (SOD, CAT and GSH) in the brain homogenates and serum respectively. In the brain homogenates, there was significant ( $\mathrm{p}<$ 0.05 ) increase in the level of catalase (CAT) enzyme activity in the treated group and the control drug groups (SS and DPZ) when compared with the untreated LPS-induced group. The group treated with $\mathrm{BF}$ and $\mathrm{CM}$ extract showed better increase in the serum, whereas, only the CM treated group followed the same trend in the brain homogenate. The glutathione reductase (GSH) contents in all the experimental groups of mice showed significant increase $(p<0.05)$ when compared with the untreated LPS-induced group especially in the serum. There was no significant difference in the superoxide dismutase (SOD) activity in all experimental groups both in the brain homogenates and serum. 
Table 1: Effect of Oral Administration of Three Medicinal Plants for 7 days in Brain Antioxidant Status of Mice Treated with LPS

\begin{tabular}{cccr}
\hline Treatment & SOD $(\mathbf{U} / \mathbf{m g}$ protein) & CAT (nmol/mg protein) & $\begin{array}{c}\text { GSH (nmol/min } \\
\text { /mg protein) }\end{array}$ \\
\hline Vehicle & $97.86 \pm 0.71$ & $1287.57 \pm 110.6$ & $223.9 \pm 0.23$ \\
Vehicle+LPS (250g/kg & $96.43 \pm 0.92$ & $911.84 \pm 96.4^{*}$ & $220.1 \pm 1.21^{*}$ \\
Vehicle +LPS+SS & $96.79 \pm 0.68$ & $925.20 \pm 28.8^{* \#}$ & $222.88 \pm 0.34^{* \#}$ \\
Vehicle+LPS+DPZ & $97.14 \pm 1.01$ & $979.85 \pm 30.5^{* \#}$ & $223.57 \pm 0.29^{* \#}$ \\
Vehicle+LPS+SD & $96.07 \pm 0.35$ & $1363.51 \pm 157.1^{*}$ & $22.29 \pm 1.17^{* \#}$ \\
Vehicle+LPS+BF & $95.54 \pm 0.61$ & $1029.26 \pm 63.7^{* \#}$ & $224.63 \pm 0.32^{* \#}$ \\
Vehicle+LPS+CM & $97.49 \pm 0.36$ & $929.69 \pm 63.7^{*}$ & $221.14 \pm 0.44^{*}$ \\
\hline
\end{tabular}

The mice brain biochemical parameters are expressed as mean \pm S.E.M values ( $n=5 /$ group).

Values within each column with different superscript letters $(*$ and \#) are significantly different $(\mathrm{p}<0.05) *$ when compared with Vehicle group and \#when compared with the LPS group determined using One -way ANOVA.

Table 2: Effect of Oral Administration of Three Medicinal Plants for 7 Days In Serum Antioxidant Status of Mice Treated with LPS.

\begin{tabular}{cccc}
\hline Treatment & SOD $(\mathbf{U} / \mathbf{m g}$ protein) & $\begin{array}{c}\text { CAT } \\
\text { (nmol/mg protein) }\end{array}$ & $\begin{array}{c}\text { GSH }(\mathbf{n m o l} / \mathbf{m i n} \\
\text { /mg protein) }\end{array}$ \\
\hline Vehicle & $98.28 \pm 0.29$ & $1399.40 \pm 47.45$ & $227.94 \pm 0.92$ \\
Vehicle+LPS (250g/kg & $97.5 \pm 0.68$ & $945.32 \pm 35.97^{*}$ & $223.57 \pm 0.82^{*}$ \\
Vehicle+LPS+SS & $98.29 \pm 0.29$ & $2007.36 \pm 64.92^{* \#}$ & $223.39 \pm 0.86^{*}$ \\
Vehicle+LPS+DPZ & $98.57 \pm 0.00$ & $511.17 \pm 43.02$ & $227.71 \pm 2.42^{*}$ \\
Vehicle+LPS+SD & $98.57 \pm 0.00$ & $1190.51 \pm 29.64 .1^{* \#}$ & $226.84 \pm 0.76^{*}$ \\
Vehicle+LPS+BF & $97.62 \pm 0.48$ & $390.77 \pm 39.28$ & $232.01 \pm 0.7^{* \#}$ \\
Vehicle+LPS+CM & $97.85 \pm 0.71$ & $825.79 \pm 26.56$ & $234.18 \pm 1.22^{* \#}$ \\
\hline
\end{tabular}

The mice brain biochemical parameters are expressed as mean \pm S.E.M values $(n=5 /$ group $)$.

Values within each column with different superscript letters $(*$ and \#) are significantly different $(\mathrm{p}<0.05) *$; when compared with Vehicle group and \#; when compared with the LPS group determined using One -way ANOVA

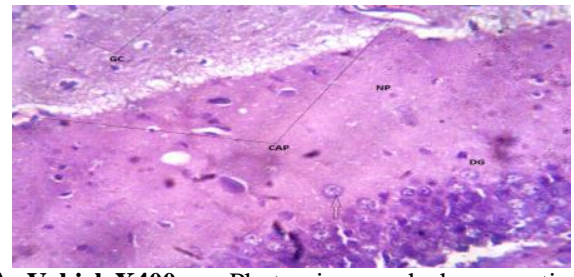

A: VehicleX400 $\boldsymbol{\mu m}$ Photomicrograph shows section of the hippocampus showing the cappilliary (CAP), glia cell (GC) and dentate gyrus (DG) composed tightly packed granule cell layer(Arrow).

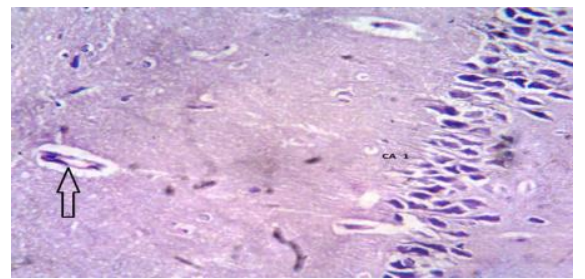

D: LPS+ DPZ $\times 400 \mu \mathrm{m}$ Photomicrograph shows the hippocampus tissue showing the moderate degenerative changes (pyknosis) within the neuron of the CA region. Arrow shows the blood vessel.

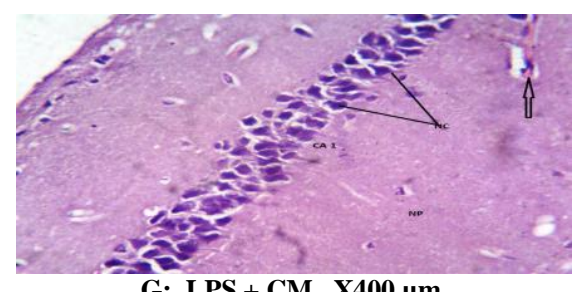

KEY: SS= Sulindac Sulfide, $\mathbf{L P S}=$

Lipopolysaccharide, $\mathbf{D P Z}=$ Donepezil, $\mathbf{S D}=$

Scoparia dulcis, $\mathbf{B F}=$ Bacopa floribunda, and $\mathbf{C M}=$

Cordia millenii

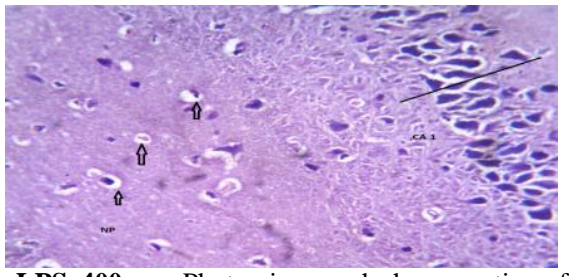

B: LPSx400 $\boldsymbol{\mu m}$ : Photomicrograph shows section of the hippocampus with mild degenerative changes within the CA strata (arrow).

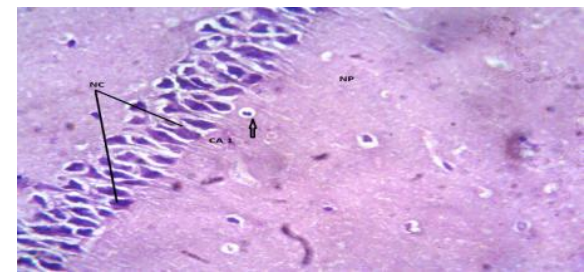

E: LPS + BF x400 $\mu \mathrm{m}$ : Appear as in Section control.

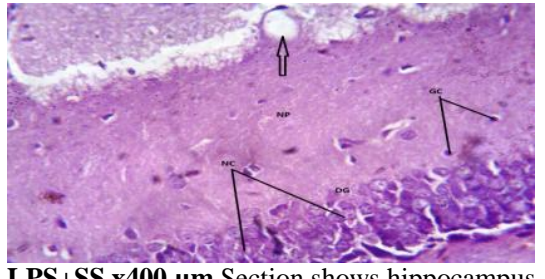

C: LPS+SS x400 $\boldsymbol{\mu m}$ Section shows hippocampus tissues composed of capillary (Arrow), glia cell (GC), nerve Cell (NC), nueropil (NP). Their histocytoarchitecture appears unremarkable.

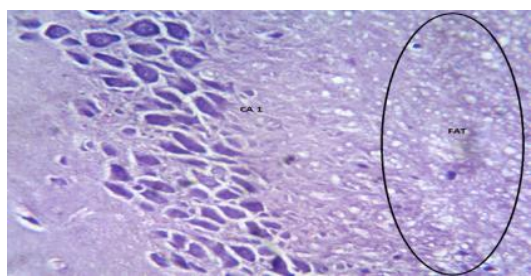

F: LPS + SD x400 $\mu \mathrm{m}$ : Section shows mild fat deposition within the CA strata.

Fig. 3A-G: Histology Showing the Haematoxylin and Eosin Staining of the Mouse Hippocampus.

\section{Histopathological Analysis of Hippocampus [Cornus Ammonis-1 (Ca1)] of LPS-Induced Neuronal Damage in Mice} Histological analyses of hippocampus in the control and experimental groups of mice were shown in Figure (3A-G).
Histological sections were imaged at a magnification of 400 . Control animals showed normal histological architecture in the hippocampus showing a distinct region of the hippocampus composed of packed cappilliary cells (CAP), glia cells (GC) and 
dentate gyrus (DG), (Fig. 3A). Neuronal cells in LPS-induced when injected intraperitoneally with $250 \mu \mathrm{g} / \mathrm{kg}$ LPS, 4 hours before mice were sacrificed was characterized by retraction of cell bodies resulting in the formation of a clear space around the degenerating neurons accompanied with pyknotic and condensed nuclear morphology within the CA strata of the hippocampus. (Fig. 3B). The Sulindac Sulfide (SS), an antiinflamatory agent, treated mice exhibited significant reduced morphologic abnormalities, a characteristic of protected cellular morphology, than that of anticholinergic standard drug Donepezil (DPZ) in the hippocampus tissue showing the moderate degenerative changes (pyknosis) within the neuron of the $\mathrm{CA}$ region. Arrow shows the blood vessel, (Fig. 3C and Fig. 3D). Among the three tested plants, Scoparia dulcis (SD) treated group showed an appreciable reduced morphologic abnormalities but leaving some traces of fat deposition within the CA strata the reason which could not yet be explained when compared to the other two sample Bacopa floribunda (BF) and Cordia millenii (CM) did not exhibit appreciable changes in the hippocampus (Fig. 3E, Fig. 3F and Fig. 3G).

\section{DISCUSSION}

Numerous factors have been reported to improve memory impairment (Tong et al., 2009), and brain antioxidant status (Nicolakakis et al., 2008). The brain and nervous system are thought to be particularly vulnerable to oxidative stress due to their limited antioxidant capacity, it consumes 20 percent of the metabolic oxygen, neurons cannot synthesize glutathione and contains more of polyunsaturated fatty acids (Marksberry and Lovell, 2007; Oboh and Rocha, 2007). Evidence shows that reactive oxygen species (ROS) mediated oxidative stress triggers apoptotic signal and subsequent neuronal death (Wang et al., 2013). These ROS was reported to be continuously produced in aerobic organisms as a byproduct of metabolism and during phagocytosis by macrophages including microglia. An imbalance in the redox homeostasis caused by ROS generation leads to deficit in cellular antioxidant defense system which in turn renders the lipids, protein and DNA vulnerable to free radical attack culminating in oxidative stress that underlies multitudinous pathologies including neurodegeneration (Aruoma, 1998; Halliwell and Gutteridge, 1999). ROS can directly attack the polyunsaturated fatty acids of the cell membranes and induce lipid peroxidation. Malondialdehyde (MDA) is the end-product of lipid peroxidation, which is a process where ROS degrade polyunsaturated fatty acids. This compound is a reactive aldehyde and is one of the many reactive electrophile species that cause toxic stress in cells and form advanced glycation end-products. The production of this aldehyde is used as a biomarker to measure the level of oxidative stress in an organism (Murray et al., 2000).

The present study has revealed that the administration of lipopolysaccharide (LPS) induced lipid peroxidation in mice brain and serum tested when compared with the control without LPS. This is in agreement with previous studies that have shown LPS to be a stimulator of lipid peroxidation (Yoshikawa et al., 1994; Stuss et al., 2010; Sewerynek et al., 2011). LPS induces the synthesis of nitric oxide by catalyzing L-arginine oxidation to citrulline and to the toxic form of nitric oxide (NO•) (Jiang-Shieh et al., 2005). The reaction of nitric oxide with superoxide anion $\left(\mathrm{O}_{2}^{\bullet-}\right)$ leads to the formation of highly toxic peroxynitrite anion (ONOO-) that can initiate lipid peroxidation of neuronal cell membranes (Jiang-Shieh et al., 2005). However, our results clearly show that all the plant extracts tested decreased lipid peroxidation, previously induced by LPS, in the brain and serum examined tissue (Fig. 1 and. Fig. 2). Additionally, sample BF exerted the strongest inhibitory effects. The inhibitory effect of the plant samples could be due to their potent antioxidant activities as evidenced by the restoration of enzymatic antioxidant activity (CAT) and non-enzymatic antioxidant (GSH) in LPS-induced oxidative neuronal damage in mice (Tables 1 and 2).

The activity of SOD is a sensitive index in oxidative damage as it scavenges the superoxide anion to form hydrogen peroxide leading to diminish the toxic effects in the brain (Khan et al., 2012). However, there was no significance difference in the SOD activities both in the blood serum and the brain homogenate of this study. The reason for this could not be categorically stated, but may be reasoned out that SOD being the first line of defense against ROS may remain unnoticed. The next line of antioxidant defense is the catalase (CAT) enzyme which is an enzymatic antioxidant widely distributed in all animal tissues that decompose hydrogen peroxide and protect the tissue from highly reactive hydroxyl radicals (Khan et al., 2012). The present work has revealed that the administration of the three plant extracts showed their potentials as exogenous antioxidants. Although the level of action of the CM sample seemed not to be well pronounced, however, it exhibited some level of protection against free radicals in both the blood serum and the brain.

Reduced glutathione (GSH) and glutathione reductase is thought to be the fundamental antioxidant enzymes, for they are closely related to the direct elimination of reactive oxygen species (ROS). Therefore, the reduction in the activity of these enzymes may result in a number of deleterious effects due to the accumulation of superoxide radicals and hydrogen peroxide, linked with neurodegenerative diseases (Fang et al., 2000). The brain and nervous system are thought to be particularly vulnerable to oxidative stress due to their limited antioxidant capacity and reduced glutathione level (Marksberry and Lovell 2007; Oboh and Rocha 2007). The administration of LPS caused a reduction in the GSH level, however, pre-treatment with all the plant extracts were able to spare the endogenous antioxidant level in this case, GSH when compared with the control without LPS. This is probable an indication that the plants contain important antioxidant mechanism of action that can fight against the free radicals produced from LPS administration.

Histological study showed a neurodegeneration evidenced by the neuronal loss observed in the LPS treated group. To determine whether animal models of neurodegenerative disorder such as AD recapitulate degeneration of specific neuronal 
types as seen in human patients, it is first necessary to evaluate whether neurodegeneration occurs in animal models. It is sometimes important to establish probably at which age and in which part of the brain neurodegeneration frank loss of neurons begin and how quickly neurodegeneration progresses. Histological analysis revealed that LPS-induced mice exhibited condensed and pyknotic nuclear morphology in the hippocampus, a characteristic of severe degenerative changes. This was further corroborated with the memory impairment observed in the spatial memory function of a behavioral study carried out (data not shown). These abnormal histological architecture could be attributed to oxidative stress induced neuronal apoptosis by LPS. Protected cellular morphology discernible among the treated group animals might be due to their anti apoptotic effect as cell death modes are classified as necrosis, apoptosis, or autophagic based on the cell's morphological features (Lee et al., 2008), although the mechanism and process underlying cell death are complex and vary among different diseases. Also, neurodegeneration in $\mathrm{AD}$ has been reported to be usually accompanied by a chronic inflammatory response including glia cells and complement activation and the release of proinflamatory cytokines from glial sells (Marco et al., 2013).

\section{CONCLUSION}

Based on the present study, all the plant extracts tested prevented oxidative damage induced by administration of LPS induced neuroinflammation in mice. This activity could be attributed to their antioxidant potential as evidenced from their inhibitory effect on MDA and increased CAT activity and GSH. Nevertheless, other possible mechanisms of action against neuronal damage need to be assessed to further justify their use traditionally in the treatment/management of neurodegenerative diseases.

\section{Financial support and sponsorship: Nil.}

Conflict of Interests: There are no conflicts of interest.

\section{REFERENCES}

Akrout, N., Shar shar, T., Annane, D. Mechanisms of brain signaling during sepsis. Curr. Neuropharmacol. 2009; 7, 296-3 01.

Aruoma, O.I. Free radicals, oxidative stress and antioxidants in hu man health and disease. J. Am. Oil Chem. 1998; 75, 199 - 212 Soc.75, 199 - 212 . Halliwell, B., Gutteridge, J.M., 1999. Free Radicals in Biology and Medicine, 3rd ed. Clarendon Press, Oxford, UK.

Ching, S., Zhang, H., Belevych, N., He, L., Lai, W., Pu, X.A., Jaeg er, L.B., Chen, Q., Quan, N. Endothelial-s pecific knoc kdown of interleukin-1 (IL-1) type 1 receptor differentially alters CNS responses to IL-1 depending on its route of admi nistration. J. Neurosci. 2007; 27, 10476 - 10486.

Dastmalchi K, Dorman HJD, Vuorela H, Hiltunen R. Plants as potential sources for drug development against Alzheimer's disease. Intl J Biomed Pharma Sci. 2007; 1(2):83-104.

Dobrovolskaia, M.A., Vogel, S.N. Toll receptors, CD14, and macrophage activation and deactivation by LPS. Microbes Infect. 2002; 4, 903-914.

Durairajan S.S, Yuan Q, Xie L, Chan W.S, Kum W.F, Koo I, Liu C, Song Y, Huang J.D, Klein WL, Li M. Salvianolic acid B inhibits $\mathrm{A} \beta$ fibril formation and disaggregates preformed fibrils and protects against A $\beta$-induced cytotoxicty. Neurochem Intl. 2008; 52:741-750. Publisher Full Text.

Frank, B., Gupta, S. A review of antioxidants and Alzheimer's disease. Annals of Clinical Psychiatry 2005; 17: 269-286.

Halliwell, B., Gutteridge, J.M. Free Radicals in Biology and Medicine, 1999 3rd ed. Clarendon Press, Oxford, UK.

Jiang-Shieh Y.F, Wu C.H, Chien H.F, et al. Reactive changes of interstitial glia and pinealocytes in the rat pineal gland challenged with cell wall components from gram-positive and -negative bacteria. J Pineal Res. 2005; 38: 17-26.

Khan R.A 1, Khan M.R and Sahreen S.S. Brain antioxidant markers, cognitive performance and acetylcholinesterase activity of rats: efficiency of Sonchus asper. Behavioral and Brain Functions 2012, 8:21 doi:10.1186/1744-9081-8-21.

Kheir-Eldin, AA, Motawi, TK, Gad, MZ, Abd-ElGawad, HM. Protective effect of vitamin $\mathrm{E}$, beta-carotene and $\mathrm{N}$-acetylcysteine from the brain oxidative stress induced in rats by lipopolysaccharide. Int. J. Biochem. Cell Biol. 2001; 33, 475-482.

Kumagai S, Jikimoto T, Saegusa J. Pathological roles of oxidative stress in autoimmune diseases. Rinsho Byori. 2003; 51(2): 12632.

Kumar S, Brijeshlata and Dixit S. Screening of traditional Indian spices for inhibitory activity of acetylcholinesterase and butyrylcholinesterase enzymes. International Journal of Pharma and Bio Sciences. 2012 3(1): 59-65.

Lee J.W, Lee, YK, Yuk DY, Choi DY, Ban SB, Oh KW, Hong JT. Neuro-inflammation induced by lipopolysaccharide causes cognitive impairment through enhancement of $\beta$ - amyloid generation. $J$. Neuroinflamm. 2008; 5, 37.

Marco A. Meraz-Ríos, Danira Toral-Rios, Diana FrancoBocanegra, Juana Villeda-Hernández, and Victoria Campos-Peña. Inflammatory process in Alzheimer's disease. Front Integr Neuroscience. 2013; 7: 59.

Marksberry WR, Lovell MA. Damage to lipids, proteins, DNA and RNA in mild cognitive impairment. Arch Neurology 2007; 64:954956.

Min SS, Quan HY, Ma J, Han J, Jeon HB, Seol GH. Chronic brain inflammation impairs two forms of long-term potentiation in the rat hippocampal CA1 area. Neuroscience Letter. 2009; 456: 20-24.

Mulkey DK, Henderson RAIII, Putnam RW, and Dean JB. Hyperbaric oxygen and chemical oxidants stimulate $\mathrm{CO} 2 / \mathrm{H}+-$ sensitive neurons in rat brain stem slices. J. Appl. Physiol., 2003; 95: 910-921. Murray R.K, Granner D.K, Mayes P.A, Rodwell V.W. Harper's biochemistry. 2000; 25th ed: p. 927.

Nathan, C. Points of control in inflammation. Nature 2002; 420 (6917), 846-852.

Nicolakakis, N., T. Aboulkassim, B. Ongali, C. Lecrux, P. Fernandes, P. Rosa-Neto, X.K. Tong and E. Hamel. Complete rescue of cerebrovascular function in aged Alzheimer's disease transgenic mice by antioxidants and pioglitazone, a peroxisome proliferator-activated receptor gamma agonist. J. Neurosci., 2008; 28: 9287- 9296.

Norton S, Matthews FE, Barnes DE, Yaffe K, Brayne C. Potential for primary prevention of Alzheimer's disease: an analysis of population-based data. Lancet Neurol. 2014; 13: 788-794.

Oboh G, Rocha JBT. Polyphenols in red pepper [Capsicum annuum var. Aviculare Tepin)] and their protective effect on some prooxidants induced lipid peroxidation in brain and liver. European Food Research Technology. 2007; 225:239-47.

Oboh G, Akinyemi AJ and Ademiluyi AO. Antioxidant and inhibitory effect of red ginger (Zingiber officinale var. Rubra) and white ginger (Zingiber officinale Roscoe) on $\mathrm{Fe}^{2+}$ induced lipid peroxidation in rat brain in vitro. Experimental and Toxicologic Pathology. 2012; 64(1-2): $31-36$.

Ohkawa H, Ohishi N, Yagi K. Assay for lipid peroxides in animal tissues by thiobarbituric acid reaction. Anal Biochem 1979; 95:351- 358

Oken BS, Storzbach DM, Kaye JA. The efficacy of Ginkgo biloba on cognitive function in Alzheimer disease. Arch Neurol. 1995; 55:1409-14015 
Okun E, Griffioen K, Barak B, Roberts NJ, Castro K, Pita MA, Cheng A, Mughal MR, Wan R, Ashery U, Mattson MP. Toll-like receptor 3 inhibits memory retention and constrains adult hippocampal neurogenesis. Proc. Natl. Acad. Sci. USA 2010; 107, 15625-15630.

Perry G, Cash AD, Smith MA. Alzheimer disease and oxidative stress. J Biomed Biotechnol. 2002; 2(3):120-123.

Pratico D, Delanty N. Oxidative injury in diseases of the central nervous system: focus on Alzheimer's disease. Am J Med 2000; 109:577585 .

Qin L, Wu X, Block ML, Liu Y, Breese GR, Hong JS, Knapp DJ, Crews FT. Systemic LPS causes chronic neuroinflammation and progressive neurodeg eneration. Glia. 2007; 55, 453 - 462 .

Sebai H, Gadacha W, Sani M, Aouani E, Ghan em-Boughanmi N, Ben-Attia M. Protective effect of resveratrol against lipopolysaccharide-ind uced oxidative stress in rat brain. Brain Inj. 2009; 23, 1089-1094 .

Sewerynek E, Wiktorska JA, Stuss M. 6-methoxytryptophol reduces lipopolysaccharide-induced lipid peroxidation in vitro more effectively than melatonin. Journal of Physiology and Pharmacology, 2011; 62(6), 677-683.

Skolnick AA. Old Chinese herbal medicine used for fever yields possible new Alzheimer disease therapy. J Am Med Assoc. 1997; 277: 776.

Stuss M, Wiktorska J.A, Sewerynek E. N-acetylserotonin reduces lipopolysaccharide-induced lipid peroxidation in vitro more effectively than melatonin. Neuro Endocrinol Lett. 2010; 31: 489-496.

Streit WJ, Mrak RE, Griffin WS. Microglia and neuroinflammation: a patholog ical perspective. J. Neuroinflamm. 2004; 1, 14.
Terry RD, Masliah E. Physical basis of cognitive alterations in Alzheimer's disease: Synapse loss is the major correlate of cognitive impairment. Ann Neurol. 1991; 30: 572-80.

Tong XK, Nicolakakis N, Fernandes P, Ongali B, Brouillette J, Quirion R and Hamel E. Simvastatin improves cerebrovascular function and counters soluble amyloid-beta, inflammation and oxidative stress in aged APP mice. Neurobiol. Dis., 2009; 35: 406-414.

Wang TF, Lei Z, Li YX, Wang YS, Wang J, Wang SJ, Hao YJ, Zhou R, Jin SJ, Du J, Li J, Sun T, Yu JQ. Oxysophoridine protects against focal cerebral ischemic injury by inhibiting oxidative stress and apoptosis in mice. Neurochem. Res. 2013; 38, 2408-2417.

Yoshikawa T, Takano H, Takahashi S, Ichikawa H, Kondo M. Changes in tissue antioxidant enzyme activities and lipid peroxides in endotoxin-induced multiple organ failure. Circ Shock. 1994;42: 53-58.

\section{How to cite this article:}

Olatunji BP, Fasola TR, Onasanwo SA, Akinyemi AJ, Adeniyi PA, Ishola AO. Neuronal Alterations and Antioxidant Status of Lipopolysaccharide Induced Neuronal damage in Mice: Efficacy of Three Medicinal Plants. J App Pharm Sci, 2017; 7 (12): 156-162. 